\title{
Validate the Use of College Self Efficacy Inventory for Measuring Psychosocial Factors on Indian Students
}

\author{
Dr. Rachna Jain ${ }^{1}$, Ms. Bharti Chaudhary ${ }^{2}$
}

\section{ABSTRACT}

The purpose of this study was to apply the College Self-Efficacy Inventory (CSEI) scale to measure the social and psychological factors on Indian students. The major research question of the study is to answer whether the CSEI scale fit the data. The sample of the study is 141 in BBA and B.Com $(\mathrm{H})$ first year in affiliated college of Guru Gobind Singh Indraprastha University Delhi. Path analysis has been used in the study to examine the interrelationship between courseroommate-social self-efficacy. To analyse the data correlation, CFI, RMSEA, Cron bach alpha, regression weights, Durbin - Watson test etc. has been used. The study found affirmative steps in collecting validity evidence for the CSEI scale as well as found significant inter - relationship between course-roommate-social self-efficacy of Indian undergraduate students. It has been also found that CSEI scale can be used to measure college self- efficacy for the broader college experience of Indian students.

Keywords: Self-efficacy, CSEI, students, Path analysis, relationship

College student adjustment process has been gaining importance in order to increase the satisfaction level of the students due to increasing complexities of the environment. The process has been explored in different contexts such as social, academic, motivational, psychosocial, and personality. One specific construct that has received considerable interest in the domain of college student adjustment is self-efficacy to organize and execute courses of action required to attain designated types of performances (Bandura, 1986, p. 391).

It has been suggested that self-efficacy is important to not only the academic and social adjustment of students but to their overall wellness and personal adjustment as well (e.g., DeWitz \& Walsh, 2002; Gore, 2006; Solberg \& Villareal, 1997). Self-efficacy is viewed as a person's perception of his or her capabilities to attain a specific goal or task (Bandura, 1993, 2000).

${ }^{1 \& 2}$ Assistant Professor, Maharaja Agrasen Institute of Mnagement Studies (affiliated to GGSIP University), Sector - 22, PSP Area, Rohini, Delhi)

(C) 2015 I R Jain, B Chaudhary; licensee IJIP. This is an Open Access Research distributed under the terms of the Creative Commons Attribution License (http://creativecommons.org/licenses/by/2.0), which permits unrestricted use, distribution, and reproduction in any Medium, provided the original work is properly cited. 


\section{Validate the Use of College Self Efficacy Inventory for Measuring Psychosocial Factors on Indian Students}

Self-efficacy, rooted in Bandura's social-cognitive theory (Bandura, 1986), is related to a number of educational and psychological constructs. As stated by socio-cognitive theory, efficacy beliefs coupled with goal systems are able to strengthen motivation and performance through increasing effort or persistence (Bandura, 2001) and higher level of self-efficacy equates with embarking on higher levels of goals over time (Locke \& Latham, 1990).

Self-efficacy progresses in stages when an individual moves on through life's various phases (Azar \& Fatemeh, 2014). The first stage of self-efficacy development is within the student's family environment and its progress continues with age because of being exposed to models and the sense of progress which derives from mastery experiences. Peers also exert vulnerable effect on the individuals' efficacy beliefs (Bandura, 1986). In case of reassessing their competence, children's self-perceptions may shift while going through a developmental process (Marsh, Craven, \& Debus, 1999, Yeung, Lau, \& Nie, 2011).

Self-efficacy has been linked to motivational constructs such as persistence and goals/goal setting (e.g., Multon, Brown, \& Lent, 1991; Schunk \& Ertmer, 1999), the use of strategies such as self-regulated learning (e.g., Pintrich\& DeGroot, 1990), actual achievement (e.g., Pajares \& Miller, 1995), and affective constructs such as stress and distress and anxiety (e.g., Finney \& Schraw, 2003; Solberg \& Villareal, 1997). One important character of self-efficacy is that it is domain specific; that is, self-efficacy judgments are specific to certain tasks in certain situations (Bandura, 1977, 1986, 1997). Researchers have shown the strongest link between self-efficacy and outcomes when the specificity of the efficacy assessment and the criterion matches (Choi, 2005; Pajares \& Miller, 1995).

Self-efficacy has been studied within a variety of specific domains such as academic, social, career, clinical, athletics, and health areas (Bandura, 1997). Self-efficacy in the academic domain has been widely studied with college students with college-aged populations because both are integral components of the college experience. Self-efficacy results were significantly related to hope level in education systems( Davidson et al., 2012). A gender study on college students suggest that perceived self-efficacy must be taken into consideration (Chavez et al., 2014). It has been found that academic achievements can be enhance by increasing their self- efficacy through applying training methods and enriching educational environments( Jahanian \& Mahjoubi, 2013). Recently, a new domain of self-efficacy beliefs has been proposed for the college student: that of college self-efficacy. College self- efficacy is the degree of confidence students have for completing college-related tasks (Barry \& Finney, 2007).

Few scales have been developed to measure general self- efficacy like academic Self-Confidence subscale of the Student Readiness Inventory (ASC; Le, Casillas, Robbins, \& Langley, 2005) and the College Academic Self-efficacy Scale (CASES; Owen \& Froman, 1988) are the examples of general measures. The CSEI was developed (Solberg et al.1993) in order to understand the role 
of self-efficacy in the college adjustment. The college self-efficacy inventory was first developed to understand the role of self-efficacy in the process of college adjustment(Solberg et al.1993).College self-efficacy inventory scale (CSEI) has been applied to establish a retention strategy for freshmen African American males and revealed that it is associated with student's academic success.Social self-efficacy, Roommate self- efficacy and course self-efficacy were three psychosocial factors that were analyzed and found that these factors have been associated with student's academic success and retention (Dauvell, 2013).

\section{PURPOSE OF THE STUDY:}

The major research question of the study is to answer "Does the CSEI scale fit the data?" The other purpose of the study was to examine the interrelationship between course self-efficacy, roommate self-efficacy and social self-efficacy with undergraduate students. The goal was to understand the applicability of College Self efficacy Inventory Scale (CSEI) on students. From the previous studies, it has been found that CSEI is applied with Turkish students, Hispanic students, African American etc. but not yet examined specifically with Indian students. This study could be helpful in measuringand understanding the psychosocial factors of the Indian student. The focus of research was to assess college self-efficacy, or "the degree of confidence students have in their ability to successfully perform a variety of college-related tasks"”, (Solberg,1993). The CSEI would be used to measure self-efficacy for the broader college experience.

\section{RESEARCH METHODOLOGY}

The study has used CSEI scale to measure the college self-efficacy which was developed by Solberg (Solberg et al., 1998). The studyspecified three psychosocial factors: Course Efficacy, Roommate Efficacy, and Social Efficacy. The scale consisted of 20 items with three broad categories: course self-efficacy, roommate self-efficacy and social self-efficacy. Course selfefficacy consists of 7items (e.g.. "Participate in class discussion"). Roommateself-efficacy consist of 4 items (e.g.. "Get along with others you live with "). Social self- efficacy consists of 9 items.Both the Roommate and Social subscales were social in nature, but the Roommate items were more specific to social interactions with those you live with, whereas the Social items were largely specific to social interactions in the classroom or with university staff.CSEI instrument is 10 point scale to rate the confidence. This three-factor model has received some support throughout the literature (Gore et al., 2006; Solberg et. al., 1993).

CSEI data were collected from 156 undergraduate students. Cases with incomplete data and duplicate cases were removed to yield a total sample of 141. All undergraduate students are studying in BBA and B.Com $(\mathrm{H})$ first year in affiliated college of Guru Gobind Singh Indraprastha University Delhi. Convenient sampling method has been used for data collection.

To analyze the data Amos 22 and SPSS 22 software were used. Path analysis has been done in the study to examine the interrelationship between course-roommate-social self-efficacy.The 
correlations among the 20 items of CSEI scale have been calculated. To understand the applicability of College Self efficacy Inventory Scale (CSEI) on India students model fit has been investigated .Comparative fit index, Root Mean Square Error of Approximation, Goodness of fit index and CMIN (minimum sample discrepancy) have been analyzed to check the model fit in the sample. Standard regression weights have been computed to check the factor loading of each item. Durbin Watson statistics used to check the problem of auto correlation among items in data. Other statistics like Mahalanobis distance (Multi- collinearity problem), Cronbach alpha (reliability of CSEI scale) etc. have been calculated to examine the sample data.

\section{RESULTS AND ANALYSIS}

Correlation has been analyzed to measure the strength and direction of the linear relationship between 20 items. The study found (Table 1) that course self-efficacy (item 1/item 4) is strongly and positively correlated (0.715/0.712)to social self-efficacy (item 8/item 6). Course selfefficacy (item 2) is highly correlated with course self- efficacy (item 3) but moderately correlated with roommate and social self-efficacy. Corse self-efficacy (item 3/item 6) is strongly correlated with one of the item of each factors ofcourse-roommate-social (0.719-0.720-0.746$0.717 / 0.720-0.746-0.717)$. This item "Do well in your exams" is the most important parameter of college self-efficacy of the first year students. Course self -efficacy (item 5) is highly correlated with course self- efficacy (item6) and social self -efficacy (item 1). Course self efficacy (item 7) and Roommate self - efficacy (item 2) is moderately correlated with all other 19 items. Roommate self- efficacy (item 1$)$ is directly correlated with social factors (0.729/ 0.705/ 0.712).Roommate self -efficacy (item3) is strongly correlated with both course(item $3 \&$ item 6) and social factors (item 1\&item 8).Roommate self -efficacy (item4) is poorly correlated with other factors. All items of social self-efficacy are inter-correlated with each other \{example: social self- efficacy item 6 is positively and strongly correlated with social selfefficacy item5 (0.702) and item $7(0.710)$ \}. The study shows that the 20 items taken in CSEI scale have positive correlation among them (Table 1 ).

The analysis shows that interrelationship between courses self -efficacy factor withroommate as well as social self- efficacy factor is positively strong. The study also found that all the three factors are strongly and positively inter-correlated (Table 2). 
Validate the Use of College Self Efficacy Inventory for Measuring Psychosocial Factors on Indian Students

Table 1: Correlation Matrix

CORRELATION Matrix B/W 20 Items

\begin{tabular}{|c|c|c|c|c|c|c|c|c|c|c|c|c|c|c|c|c|c|c|c|c|}
\hline ES & SE1 C & SE2 & CSE3 & CSE4 & CSE5 & CSE6 & CSE7 & RSE1 & \begin{tabular}{|l|l|} 
RSE2 & |
\end{tabular} & RSE3 & SE4 & SSE1 & SSE2 & SSE3 & SSE4 & SSE5 & SSE6 & SSE7 & SSE8 & \\
\hline & & .637 & 615 & .553 & .557 & .620 & .515 & .613 & .475 & .649 & .451 & .587 & .497 & .673 & .565 & .516 & .547 & .572 & .715 & \\
\hline & & 1.000 & .719 & .602 & .571 & .539 & .536 & 610 & 590 & .666 & .565 & 612 & .477 & .646 & .538 & .494 & . 465 & 579 & 651 & \\
\hline & 615 & .719 & 1.000 & .610 & .680 & .720 & .679 & .694 & .674 & .746 & .588 & .717 & .579 & .582 & . 488 & .617 & .626 & .625 & .600 & 61 \\
\hline & 53 & .602 & .610 & 1.000 & .541 & .651 & .618 & .696 & .539 & .669 & .365 & .571 & .591 & .564 & .465 & .545 & .712 & .590 & .496 & .50 \\
\hline & .557 & .571 & 680 & .541 & 1.000 & .734 & .578 & 688 & .643 & .681 & .481 & .779 & .497. & .610 & .572 & .555 & .516 & .563 & .577 & \\
\hline & 620 & .539 & .720 & .651 & .734 & 1.000 & .692 & 676 & .592 & .746 & .479 & .717 & .627 & .568 & .532 & .595 & .670 & .557 & .558 & \\
\hline & 15 & .536 & .679 & .618 & .578 & .692 & 1.000 & .634 & .523 & .688 & .323 & .680 & .696 & .509 & .470 & .598 & .697 & .622 & .474 & \\
\hline & & .610 & .694 & .696 & 688 & .676 & .634 & 1.000 & .590 & .676 & .518 & .729 & .680 & .608 & .508 & .649 & .705 & .712 & .629 & \\
\hline & & .590 & 674 & & .643 & .592 & .523 & .590 & 1.000 & .638 & .618 & .614 & .486 & .520 & . 4440 & 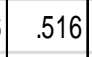 & .522 & .000 & & \\
\hline & & .666 & .746 & & .681 & & .688 & .676 & 638 & 1.000 & & & .659 & .661 & . & .021 & .000 & S & & \\
\hline SE4 & & .565 & .588 & .365 & .481 & .479 & .323 & .518 & .618 & . 468 & 1.000 & .441 & .279 & .432 & . 445 & 年 & .331 & I & 年 & \\
\hline SE1 & 587 & 612 & .717 & .571 & .779 & .717 & .680 & 729 & .614 & .772 & .441. & 1.000 & .596 & .644 & .508 & .656 & .600 & .65 & .666 & 1 \\
\hline SE2 & . 497 & . 477 & .579 & .591 & |497 & .627 & .696 & 680 & . 486 & .659 & 279 & .596 & 1.000 & .477 & .547 & .604 & .772 & .650 & . 447 & 57 \\
\hline SE3 & 73 & .646 & .582 & .564 & .610 & .568 & .509 & .608 & .520 & .661 & .432 & .644 & |477. & 1.000 & .640 & .526 & . 495 & .577 & .760 & 56 \\
\hline ST & .565 & .538 & .488 & .465 & .572 & .532 & .470 & .508 & .446 & .634 & .445 & .508 & .547 & .640 & 1.000 & .496 & .496 & . 487 & .546 & \\
\hline 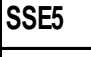 & 16 & .494 & 617 & .545 & .555 & .595 & .598 & 649 & .516 & .621 & .404 & .656 & .604 & .526 & .496 & 1.000 & .702 & .647 & .640 & 66 \\
\hline SE6 & .547 & .465 & .626 & .712 & .516 & .670 & .697| & .705 & .522 & .669 & .331 & .600 & .772 & .495 & .496 & .702 & 1.000 & .710 & .518 & 60 \\
\hline & $.5 / 2$ & .579 & .625 & .590 & .563 & .557 & .622 & .712 & .563 & .571 & .377 & .650 & .650 & .577 & .487 & .647 & .710 & 1.000 & .615 & .75 \\
\hline & .715 & .651 & .600 & .496 & .577 & .558 & .474 & .629 & .515 & .717 & .447 & .666 & .447 & .760 & .546 & .640 & .518 & |615. & 1.000 & 692 \\
\hline & 0 & .000 & 616 & .506 & .557 & .556 & .483 & .039 & . 558 & 645 & .495 & 617 & $.5 / 1$ & .562 & .511 & 667 & .607 & T & 004 & 1.00 \\
\hline
\end{tabular}

Table 2: Inter Correlation Matrix

\begin{tabular}{|l|l|}
\hline \multicolumn{2}{|l|}{ Inter Correlations b/w three factors } \\
\hline & Estimate \\
\hline CSE <--> RSE & 1.013 \\
RSE <--> SSE & .962 \\
CSE <--> SSE & .962 \\
\hline
\end{tabular}

The internal consistency reliability of CSEI scale on the given sample is examined by Cronbach's Alpha coefficient. Cronbach alpha reliability coefficient normally ranges from 0 to 1. In the sample value of alpha coefficient is 0.966 (closer to 1) which indicates higher internal consistency of the items in CSEI scale.

To analyze the research question is whether the specified model is supported by the sample data, CMIN (Normed Chi-Square), Root Mean Square Error of Approximation (RMSEA) and 
Comparative Fit Index (CFI) has been calculated. The value of RMSEA in the study is 0.00 which indicates a close fit of the model in relation to the degrees of freedom (rule of thumb: $<0.05$ ). Comparative Fit Index value is 0.85 which is closer to 1 which indicates that CSEI scale has good fit on the sample data.CMIN (Normed Chi-Square) value is 3.213 which lies in the range from 1 to 5 that proved the model fit of data (Table 3).

Table 3: Model Fit Criteria

\begin{tabular}{|l|l|l|}
\hline Model Fit Parameters & Results & Interpretation \\
\hline RMSEA & 0.00 & Value less than 0.05 indicates a good model fit \\
\hline CFI & 0.85 & Value closer to 1 reflects a good model fit \\
\hline CMIN & 3.213 & $\begin{array}{l}\text { Value Less than } 1.0 \text { is a poor model fit, More } \\
\text { than } 5.0 \text { indicates a need for improvement }\end{array}$ \\
\hline
\end{tabular}

Path analysis (figure 1) has been done to explain the interrelationship between the college selfefficacy scale factors .Standardized regression weights (Table 4) have been used tocompare direct effect on the given course-roommate-social factors in a single group study. Table 4 shows that all the 20 items of CSEI scale are greater than 0.5 which indicates none of the item is insignificant in the data. Result indicates that there is no need to remove any item of CSEI Scale (rule of thumb: Factor loading $<0.5-$ remove that factor).

Table 4: Standardized Regression Weights

\begin{tabular}{|c|c|}
\hline & Estimate \\
\hline CSE1 <--- CSE & .751 \\
\hline CSE2 <--- CSE & 844 \\
\hline CSE3 <--- CSE & .716 \\
\hline CSE4 <--- CSE & .759 \\
\hline CSE5 <--- CSE & .786 \\
\hline CSE6 <--- CSE & 802 \\
\hline CSE7 <--- CSE & .786 \\
\hline RSE4 <--- RSE & .777 \\
\hline RSE3 <--- RSE & .767 \\
\hline RSE2 <--- RSE & 661 \\
\hline RSE1 <--- RSE & .747 \\
\hline SSE9 <--- SSE & .735 \\
\hline SSE8 <--- SSE & .861 \\
\hline
\end{tabular}




\begin{tabular}{|ll|l|}
\hline & & Estimate \\
\hline SSE7 $<---$ & SSE & .566 \\
SSE6 $<---$ & SSE & .880 \\
SSE5 $<---$ & SSE & .780 \\
SSE4 $<---$ & SSE & .841 \\
SSE3 $<---$ & SSE & .802 \\
SSE2 $<---$ & SSE & .848 \\
SSE1 $<---$ & SSE & .736 \\
\hline
\end{tabular}

In the study Mahalanobis distance (Table 5) has been examined to check the problem of multicollinearity and Durbin -Watson (Table 5) has been calculated to detect the problem of autocorrelation in the data. The study found that there is a significant problem of multi-collinearity (89.54) but the problem of auto- correlation (1.956) has not been found. R- Square value 0.834 (Table 5) which demonstrate the proportion of total variation of outcomes explained by the model. It specifies how well the data fit in a statistical model.

Table 5: Estimates

\begin{tabular}{|l|l|l|l|l|}
\hline R-Square & $\begin{array}{l}\text { Adjusted } \\
\text { R-Square }\end{array}$ & Sig. F-Change & Durbin-Watson & Maha. Distance \\
\hline 0.834 & 0.806 & 0.000 & 1.956 & 89.54 \\
\hline
\end{tabular}

\section{CONCLUSIONS}

The current study has made favorable steps in collecting validity evidence for the CSEI scale on Indian students and delivers a better understanding of this measure. However building the case for validity for a particular instrument is a never ending process (e.g. Benson, 1998), and additional work is required. The current study concludes that the CSEI scale fit the data appropriately. There is significant interrelationship between course-roommate-social selfefficacy of Indian undergraduate students. It is found that scale is applicable for Indian students also. Study also explains that psychological factors needs to be understood with first year students for college self-efficacy.

In precise, it is important to reconsider the conceptualization of the college self-efficacy to make sure that all the dimensions of the college experience are effectively signified. There are other factors which influence the college experience e.g. motivation, goal choices, experiences got from family and social comparison, perception etc.

The study has not compared the scale based upon the gender differences. The study has not examined the college self-efficacy as a predictor of academic success. The study also found the problem of multi - collinearity in the data. It could be due to the repetition of same kind of items in the scale or factors are highly correlated to each other (Table 2). The study concludes that the degree of confidence of Indian students can be measured through social self-efficacy, course 
self-efficacy and roommate self-efficacy. The future researcher can explore that academic success can be achieved through enhancing self-efficacy.

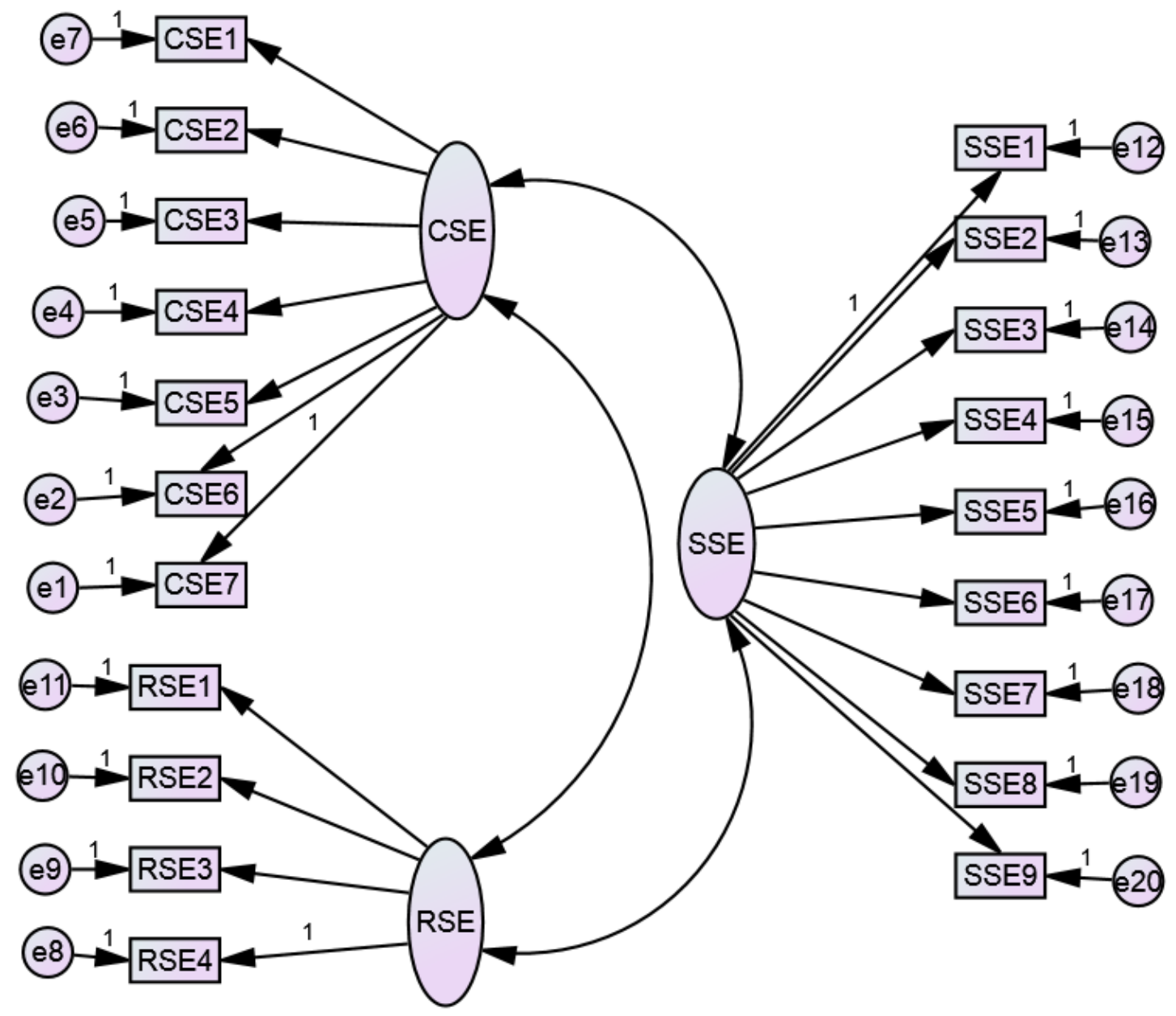

Figure 1: Path Analysis Diagram

\section{REFERENCES}

AS Yeung, S Lau, Y Nie (2011). Primary and secondary students' motivation in learning English: Grade and gender differences. Contemporary Educational Psychology 36 (3), 246-256.

Ahmed Elhassan Hamid Hassan1, Abdulaziz Alasmari 2, Eldood Yousif Eldood Ahmed3 (2015). Influences of Self Efficacy as predictors of academic achievement: A case study of special education students- University of Japan. International Journal of Education and Research. 3 (3), March, 275-278.

Azar Hosseini Fatemi, Fatemeh Vahidnia (2014). Students' educational level and their goal choices, self-efficacy, motivation, and writing performance. International Journal of Research Studies in Education 3. 


\section{Validate the Use of College Self Efficacy Inventory for Measuring Psychosocial Factors on Indian Students}

Bandura, A. (1977). Self-efficacy: Toward a unifying theory of behavioral change.Psychological Review, 84, 191-215.

Bandura, A. (1986). Social foundations of thought and action: A social cognitive theory. Englewood Cliffs, NJ: Prentice Hall.

Bandura, A. (1993). Perceived Self - Efficacy in cognitive development and functioning. Edu. Psychology, 28, 117 - 148.

Bandura, A. (1997). Self-Efficacy: The exercise of control. New York, NY W.H.Freeman and Company.

Bandura , A. (2000). Cultivate Self-efficacy for personal and organizational effectivenessIn: Blackwell Handbook of Principles of Organizational Behaviour, Locke, EA. (Ed.), Oxford, Malden, MA, 120 -136.

Bandura , A. (2001). Social Cognitive Theory: An Agentic Perspective. Annual Review Psychology. Vol. 52, 1 - 26.

Barry, C. L., \& Finney, S. J (2007, October). A Psychometric Investigation of the College SelfEfficacy Inventory. Paper presented at the annual meeting of the Northeastern Educational Research Association, Rocky Hill, CT.

Choi, N. (2005). Self-efficacy and self-concept as predictors of college students' academic performance. Psychology in the Schools, 42, 197-205.

DeWitz, S. J., \& Walsh, W. B (2002). Self-efficacy and college student satisfaction.

Journal of Career Assessment, 10, 315-326.Hispani college students. Hispanic Journal of Behavioral Sciences, 19, 182-201.

Evans, Dauvell K (2013). Examining the use of the College Self-Efficacy Inventory to establish a retention strategy for incoming African American freshmen males. Ph.D., Capella University, 2013, 84 pages; 3557379.

Gore, P. A. (2006). Academic self-efficacy as a predictor of college outcomes: Two incremental validity studies. Journal of Career Assessment, 14, 92-115.

Juan Francisco Aguirre Chavez, Francisco Muñoz Beltran, Alejandro Chavez Guerrero, Maria del Carmen Zueck Enriquez, Jesus Jasso Reyes (2014).Gender study on college students' academic self-efficacy. Science Journal of Education 2014; 2(6), 180-184.

Locke, E.A., \& Latham, G.P. (1990). A theory of goal setting and task performance. Englewood 


\section{Validate the Use of College Self Efficacy Inventory for Measuring Psychosocial Factors on Indian Students}

Cliffs, NJ: Prentice-Hall. Locke, E.A., \& Latham, G.P. (2002).

Le, H., Casillas, A., \& Robbins, S. B. (2005). Motivational and skills, social, and self-management predictors of college outcomes: Constructing the Student Readiness Inventory. Educational and Psychological Measurement, 63, 482-508

Marsh, H. W., Craven, R., \& Debus, R. (1999). Separation of competency and affect components of multiple dimensions of academic self-concept: A developmental perspective MerrillPalmer Quarterly, 45, 567-601.

Multon, K. D., Brown, S. D., \& Lent, R. W. (1991). Relation of self-efficacy beliefs of academic outcomes: A meta-analytic investigation. Journal of Counseling Psychology, 38, 30-38.

Oranit B. Davidson ${ }^{\mathrm{a}}$, David B. Feldman ${ }^{\mathrm{b}}$ \& Malka Margalit(2012). A Focused Intervention for 1st-Year College Students: Promoting Hope, Sense of Coherence, and Self-Efficacy. The Journal of Psychology: Interdisciplinary and Applied, Volume 146, Issue 3, 333-352.

Owen, S. V., \& Froman, R. D. (1988, April). Development of the College Academic Self-Efficacy Scale. Paper presenting at the annual meeting of the National Council on Measurement in Education, New Orleans, LA.

Pajares, F., \& Miller, M. D. (1995). Mathematics self-efficacy and mathematics performance. The need for specificity of assessment. Journal of Counseling Psychology, 42, 190-198.

Pintrich, P. R., \& DeGroot, E. V. (1990). Motivational and self-regulated learning components of classroommate academic performance. Journal of Educational Psychology, 82,33-40.

Schunk, D. H., \& Ertmer, P. A. (1999). Self-regulatory processes during computer skill acquisition: Goal and self-evaluative influences. Journal of Educational Psychology, 91, 251-260.

Solberg, V. S., \& Villareal, P. (1998). Examination of self-efficacy, social support, And stress as predictors of psychological and physical distress among Finney, S. J., Schraw, G. (2003). Self-efficacy beliefs in college statistics courses.Contemporary Educational Psychology, 28, 161-186.

Solberg, V. S., O’Brien, K., Villareal, P., Kennel, R., \& Davis, B. (1993). Self-efficacy and Hispanic college students: Validation of the College Self Efficacy Instrument. Hispanic Journal of Behavioral Sciences, 15, 80-95. 